\title{
Días de mucho, vísperas de nada. Mujeres y trabajos en la economía popular
}

\author{
Days of much, vespers of nothing. Women and jobs in the popular economy \\ Mariana Frega \\ Grupo de Estudio sobre Politicas Sociales y Condiciones de Trabajo, Instituto de Investigaciones Gino Germani, \\ Universidad de Buenos Aires, Argentina \\ marianafrega.s@gmail.com
}

\begin{abstract}
RESUMEN:
Este artículo se propone contribuir al análisis de las condiciones de inserción laboral de las mujeres de la economía popular en el contexto reciente. Se comparten en este trabajo algunos resultados de una investigación que realicé en dos barrios populares del Conurbano bonaerense en el marco de la elaboración de mi tesis de maestría. A partir de los resultados allí obtenidos, intento abordar algunas dimensiones clave que atraviesan las trayectorias de las trabajadoras integrando la perspectiva de género para una comprensión integral del objeto de estudio. Una de las principales conclusiones que arroja mi investigación es que en la matriz de la economía popular se evidencia la imbricación de mecanismos de opresión y explotación capitalista y patriarcal que operan sobre los cuerpos feminizados de las clases populares que padecen con mayor crudeza el deterioro de las condiciones de vida y trabajo.

Palabras Clave: Trabajo, Género, Economía Popular.
\end{abstract}

\section{ABSTRACT:}

This article aims to contribute to the analysis of the labor insertion conditions of women in the popular economy in the recent context. Some results of an investigation carried out in two popular districts of the Conurbano bonaerens are shared in this work in the framework of the elaboration of my master's thesis. Based on the results obtained there, I try to address some key dimensions that cross the trajectories of the workers integrating the gender perspective for a comprehensive understanding of the object of study. One of the main conclusions of my research is that in the matrix of the popular economy there is evidence of the overlapping of capitalist and patriarchal oppression and exploitation mechanisms that operate on the feminized bodies of the popular classes that suffer more harshly the deterioration of living and working conditions.

KeYWORDS: Work, Gender, Popular Economy.

\section{INTRODUCCIÓN}

La perspectiva de género y las contribuciones más recientes desde la economía feminista han dotado al campo de la investigación social de nuevas herramientas para la comprensión de las desigualdades sociales y económicas que persisten. En particular, la integración de estas perspectivas al estudio del trabajo en los sectores populares posibilita el abordaje de problemáticas que emergen en el marco de nuevas reconfiguraciones del sistema capitalista. Esta combinatoria de herramientas teórico-metodológicas brinda un marco sólido para el análisis de distintas dimensiones que se ponen en juego: los modos en que se ordena y organiza la división sexual del trabajo, el fenómeno de la informalidad y la precariedad laboral, ${ }^{1}$ el contenido sexista y racista de las estructuras del mercado de trabajo, la invisibilidad de las tareas de reproducción de la fuerza de trabajo, entre otras. La incorporación del género como una categoría de peso, permite entonces comprender de manera integral cuáles son los mecanismos y dinámicas que operan específicamente sobre las condiciones de vida de las trabajadoras y los trabajadores. La precariedad e informalidad a las que se ven expuestas los trabajadores en general, y las mujeres en particular, tiene entre sus consecuencias la discontinuidad en su inserción laboral, así como cambios continuos en la carga horaria que afectan 
la regularidad de los ingresos obtenidos. Esto determina transformaciones constantes en la organización doméstica de las familias y en las propias trayectorias laborales de las mujeres mucho más que en el caso de los varones (Muñiz Terra, Roberti, Deleo y Hasicic, 2013).

Este artículo se propone reflexionar a partir de los resultados de una investigación que realicé durante 2016-2017 en el marco de la elaboración de mi tesis de Maestría. ${ }^{2}$ El objetivo de aquel trabajo se orientó a comprender los factores y condiciones que atraviesan las trayectorias laborales de las trabajadoras de las clases populares. Mi recorte empírico se limitó a un sector de estas clases: aquellos hogares que acceden a la tierra y la vivienda de manera informal o por fuera del mercado inmobiliario. La realización del trabajo de campo fue dos barrios de tipo asentamiento, San Ignacio y La Morita, en el Conurbano bonaerense ${ }^{3}$ ubicados en el municipio de Esteban Echeverria perteneciente al segundo cordón.

El artículo se ordena en tres apartados: el primero consiste en el desarrollo de las principales nociones y las aproximaciones conceptuales sobre las que trabajé en mi investigación: economía popular, clases populares, estrategias de reproducción y aportes desde la perspectiva de género y economía feminista. En el segundo, presento algunos resultados y análisis que derivan de la investigación desarrollada. Por último, dejaré planteadas algunas reflexiones e inquietudes con el propósito de enriquecer el debate y las posibles líneas de indagación a futuro sobre los desafíos de las políticas públicas en el abordaje de las problemáticas laborales que enfrentan las trabajadoras de los sectores populares. Asimismo, procuro que este artículo permita (re)pensar las agendas del movimiento feminista en torno a evidenciar las necesidades concretas y las demandas específicas en torno a la precariedad de las condiciones de vida que afectan cada vez más a las mujeres.

\section{LA CENTRALIDAD DEL TRABAJO Y LA EMERGENCIA DE LA ECONOMÍA POPULAR}

Como señalan diversos estudios, la fragmentación, heterogeneidad y polarización creciente de la clase trabajadora en las últimas décadas se han convertido en un rasgo estructural que evidencia del deterioro del mercado de trabajo (Groisman, 2016). En el caso argentino, a partir de la implementación de reformas y políticas que fueron erosionando las condiciones del mundo laboral desde mediados de la década del ' 70 y profundizadas durante la década del ' 90 , se inició un proceso de crecimiento de un amplio sector de trabajadores y trabajadoras empobrecidos que se ligaron a la territorialización de la política y el mundo comunitario de los excluidos (Kessler, Svampa y Bombal, 2010). Frente a la descolectivización de la clase trabajadora, emergieron nuevas formas de organización y modalidades de trabajo que los sectores populares comenzaron a desplegar para su supervivencia cotidiana. La proliferación de nuevas actividades laborales de rebusque; el fuerte peso de las matrices político-territoriales ${ }^{4}$ que intervienen en la articulación entre políticas estatales, organizaciones sociales y hogares; la resolución de los problemas habitacionales a través de estrategias de acceso a la tierra por fuera del mercado formal son algunos de los aspectos que definen este nuevo escenario de las clases populares en la Argentina reciente.

Continuando con esta caracterización, dentro de las propiedades que caracterizan a los sectores populares 5 se puede identificar un conjunto de condiciones que lo definen como sector: su residencia en territorios con infraestructura precaria y hábitat deficitario; bajas credenciales educativas; importante peso de relaciones de proximidad para garantizar redes que posibiliten la obtención de bienes de uso o acceso al trabajo y recursos; una fuerte dependencia del Estado para asegurar la reproducción cotidiana a partir de la presencia de políticas y programas sociales en las economías domésticas; presencia de interacciones con el hábitat degradado para la obtención de insumos para la venta o el autoconsumo; centralidad del trabajo doméstico y actividades no remuneradas para garantizar el acceso a bienes y servicios; bajo nivel de ingresos y una inserción laboral caracterizada generalmente por una vinculación precaria con el mercado de trabajo a partir del empleo informal ${ }^{6}$ y de subsistencia (Cabrera y Vio, 2014). El trabajo en todas sus expresiones 
(remunerado, asalariado, independiente, no remunerado, comunitario) conserva su centralidad como motor para los hogares de los sectores populares.

\section{ECONOMÍA POPULAR: APUNTES SOBRE SU EMERGENCIA}

La economía popular ${ }^{7}$ es un campo en construcción todavía complejo de delimitar, fuente de debates sobre su definición y especificidad. En este sentido, podemos señalar la existencia de distintas perspectivas. El enfoque al cual adscribo desde mi investigación sostiene que la economía popular es fenómeno objetivable, producto de las prácticas y estrategias de reproducción de clases populares dentro del conjunto de la economía real (Vio, 2017). En este sentido asume relevancia el abordaje de las estrategias en tanto se tratan de un conjunto de comportamientos y prácticas que -moldeadas por las condiciones materiales de existencia de los sujetos y núcleos domésticos- se despliegan con el objetivo de lograr la reproducción de la vida en sentido amplio (Gutiérrez, 2003). En este entramado se articulan al mismo tiempo la relación entre estructura e individuos, así como también los vínculos con las condiciones de clase y género que operan en su configuración.

La economía popular, en tanto matriz de estrategias específicas, es la expresión de una realidad creciente en los sectores empobrecidos de las metrópolis de América Latina que "sostienen su integración por fuera de las protecciones del trabajo asalariado y cuya satisfacción vinculada a valores de uso, básicos para la reproducción de la vida, no se resuelve exclusivamente por la vía mercantil" (Cabrera y Vio, 2014, p. 137). Asimismo, estas experiencias y realidades se constituyen en una forma específica de organización social y económica, ${ }^{8}$ cuya centralidad está en el trabajo en su acepción más amplia como principal motor, trascendiendo la lógica de la ganancia y se vincula a la reproducción ampliada de la vida. Dicha matriz de estrategias que constituye la economía popular se caracteriza por una lábil delimitación entre producción y reproducción. Sobre este aspecto radica la potencialidad de integrar la perspectiva de género al análisis de su dinámica.

Cuando me refiero a estrategias las defino como un conjunto de comportamientos y prácticas que moldeadas por las condiciones materiales y de clase de los sujetos y núcleos familiares- se despliegan con el objetivo de lograr la reproducción biológica y desarrollar recursos que permitan optimizar los aspectos materiales y no materiales de la vida cotidiana (Lepore y Salvia, 2002). Si bien hay diferentes denominaciones de estrategias (de existencia, de supervivencia, familiares de vida) retomo también la conceptualización que realiza desde la perspectiva de Bourdieu. ${ }^{9}$ La autora define a las estrategias de reproducción social como aquellas prácticas conscientes o inconscientes que realizan los sujetos y los grupos familiares para conservar o aumentar sus capitales con el objetivo de mantener o mejorar su posición en la estructura social de clases. Para esta definición señala algunos elementos que las configuran: a) el volumen y la estructura del capital que hay que reproducir (proteger y/o desarrollar); el estado del sistema de los instrumentos de reproducción institucionalizados o no (Estado, mercado de trabajo, etc.); b) el estado de la relación de fuerzas entre las clases; c) los habitus incorporados por los agentes sociales (esquemas de percepción, apreciación, acción) (Gutiérrez, 2015, pp. 51-52). En suma, todos los sujetos sociales se encuentran atravesados por una tensión entre las necesidades y las formas de satisfacerlas. ${ }^{10}$

Desde este punto de partida, si analizamos las estrategias laborales debemos considerar que los sujetos no resuelven su incorporación al mundo del trabajo de manera individual, ya que su participación en la actividad económica "está atravesada por las necesidades, condiciones de oportunidad, características y proyectos de vida de los grupos domésticos a los que pertenecen” (Escobar de Pabón y Guaygua, 2008, p. 15). Los hogares, las familias o bien las unidades domésticas (aquí utilizaremos estos términos sin precisar sus particularidades) no son ámbitos homogéneos. Dentro de estos operan mecanismos de interpretación y reproducción de lo social de manera divergente y desigual entre los miembros dependiendo del género, la edad y las posiciones que ocupan en su interior (Massa, 2010). Esto significa que lejos de pensar que el despliegue de las estrategias es un acto deliberadamente consciente, sin contradicciones y como resultado de relaciones armoniosas en 
el núcleo doméstico, estas están profundamente atravesadas por el conflicto, las tensiones y la desigual distribución de poder.

Dentro de la matriz de esta economía podemos encontrar por lo menos cuatro estrategias que definen su especificidad: a) aquellas que se vinculan a la obtención de bienes de uso; b) a la generación de ingresos; c) las desplegadas para la obtención de financiamiento y, por último, aquellas que resultan del entramado de las anteriores y que se orientan a ampliar el "fondo de reproducción de los hogares" (Cabrera y Vio, 2014). ${ }^{11}$ Las condiciones en que los trabajadores y las trabajadoras de esta economía se insertan en el mundo del trabajo hacen que los límites del trabajo mercantil se vuelvan porosos, en tanto emergen y entrecruzan otros modos de trabajo (doméstico, comunitario, de reciprocidad, etc.) necesarios para la obtención de satisfactores para la reproducción. Los trabajadores y las trabajadoras se valen de diversas estrategias para garantizar su subsistencia inmediata desplegando actividades que incluyen la autoproducción del hábitat y la vivienda.

Desde esta perspectiva, la economía popular no es una mera expresión de exclusión o marginalidad. Por el contrario, esta economía persiste de manera funcional y en permanente conexión con los circuitos económicos formales, pero desde una posición subordinada, cuya articulación permite el abaratamiento de costos para el capital: la tercerización en talleres clandestinos, las actividades de recupero de residuos y materiales para la industria, la comercialización y venta productos y bienes a través de ferias, son claros ejemplos de esta ligazón. En tal sentido, abordar este fenómeno desde las estrategias permite desplegar varios aspectos de relevancia en el estudio de los procesos sociales y económicos actuales.

Asimismo, el análisis de esta economía coloca en el centro al territorio como condición de posibilidad para el despliegue de distintas estrategias de reproducción social. El impacto que tienen las condiciones de hábitat e infraestructura de los barrios sin duda influyen en los modos en que sus habitantes disponen de acceso a la salud, educación, medios de transporte, etc. También la presencia de espacios degradados o contaminados influye en la calidad de vida de quienes allí residen. A estos aspectos se suma la distancia de los territorios respecto a los centros de actividad economía y laboral siendo un factor de importancia para las posibilidades ocupacionales de las personas. Es el propio territorio el que ofrece "oportunidades" de inserción en el mundo del trabajo como ocurre en los barrios con presencia de basurales y que tienen una importante actividad vinculada al recupero de residuos, o en aquellos dónde la política social tiene un fuerte peso a través de las cooperativas.

\section{LENTES VIOLETAS PARA OBSERVAR A LAS ECONOMÍAS POPULARES}

El conjunto de estrategias que se despliegan por los hogares de la economía popular se entremezcla de un modo abigarrado, manifestándose la interrelación y la imbricación entre las diferentes modalidades de trabajo para la obtención de ingresos y recursos para que aseguren la supervivencia. Asimismo, el trabajo doméstico no remunerado -que incluye actividades de cuidado hacia miembros del núcleo familiar- se vuelve una cuestión nodal para el análisis, ya que estas prácticas garantizan no solo la reproducción de la fuerza de trabajo, sino también, la producción de bienes, redes y recursos para la subsistencia. En este sentido, la indagación acerca de los modos y las condiciones en las que se insertan las mujeres de la economía popular en el mundo del trabajo requiere un importante ejercicio de reconceptualización de la definición de trabajo y economía. En consecuencia, fue necesario ampliar sus límites e incorporar los distintos procesos de aprovisionamiento social -visibles e invisibles, remunerados y no remunerados que se despliegan en el mercado o fuera de él- y que se ponen en juego en las trayectorias laborales de las trabajadoras.

El género, como categoría central en el análisis de las estrategias devela también esta interposición entre necesidades, posibilidades y condicionantes estructurales y sociales para el desenvolvimiento de las prácticas y recursos que se movilizan para el acceso a satisfactores. Las asimetrías entre varones y mujeres también configuran los modos en que se despliegan las estrategias laborales posibles. En tal sentido, como consecuencia de la adjudicación de roles vinculados a la reproducción social son las mujeres, quienes venden su fuerza de 
trabajo en condiciones sumamente desfavorables y en trabajos que resultan una prolongación de las tareas domésticas. Este fenómeno puede observarse en los resultados de mi investigación y en una importante cantidad de trabajos que abordan esta cuestión con mayor profundidad. Las "alternativas" laborales que muchas veces se les presentan a las mujeres refuerzan la precariedad de las condiciones de trabajo más que resultar una posibilidad real de convertirse en una fuente de trabajo rentable. El resultado es la intensificación por parte de las trabajadoras en la cantidad, extensión y nivel de exigencia de todo tipo de actividades para mantener los ingresos o proveer a los hogares de los bienes necesarios. Esto incluye, como señala Massa (2010), el "peregrinaje institucional" que implica cargar sobre sus espaldas la búsqueda de recursos (estatales y no estatales) que le permitan acceder a programas sociales que garanticen transferencias monetarias o bien bienes de uso, alimentos, ropa, calzado, materiales para las viviendas, etc.

Estas estrategias no pueden pensarse por fuera de su articulación al interior del propio hogar considerando a la edad, el género y la relación de parentesco como principios básicos que delimitan la división intrafamiliar del trabajo en relación con otros hogares, así como también en relación con el mercado, el Estado y otras instituciones de la sociedad civil (Hintze, 1987). Siguiendo a Jelin:

"la unidad familiar no es un conjunto indiferenciado de individuos. Es una organización social, un microcosmos de relaciones de producción, de reproducción y de distribución, con una estructura de poder y con fuertes componentes ideológicos y afectivos que cementan esa organización y ayudan a su persistencia y reproducción” (2010, pp. 35-36).

El devenir de las condiciones predominantemente precarias e informales de reproducción de los sectores populares puede ser observado como parte de un proceso de feminización de las economías. Las nuevas estrategias y modalidades de trabajo retoman y se sirven de los saberes domésticos y comunitarios para sustentar lo que el dinero faltante no permite garantizar en los hogares (Gago, 2014). En las intersecciones entre género, trabajo y pobreza - elementos constitutivos de mi objeto de estudio- se evidencian nuevas formas de regulación y control de la fuerza de trabajo (y de las mujeres en particular) a través de distintos mecanismos operados desde las intervenciones del Estado, siendo la economía popular una expresión vital de este proceso.

Para analizar este proceso, las contribuciones de la economía feminista (Pérez Orozco, 2014; Rodríguez Enríquez, 2015; Carrasco, 2006, entre otras) han dotado de robustez a nuevas herramientas de análisis que permitieron ampliar las nociones acerca del trabajo y las dinámicas de los hogares. Asimismo, permiten comprender el peso del trabajo doméstico y de cuidados en el funcionamiento de la economía en general, el sesgo sexista de las intervenciones del Estado en relación con el problema de la pobreza y el empleo, y principalmente, el quiebre de la mirada androcéntrica sobre los procesos económicos en estas latitudes. Sobre estas primeras nociones el encuentro entre estos campos de estudio me permitió a su vez otorgar mayor integralidad al análisis de las condiciones de vida de las clases populares, de igual modo que posibilitó indagar en el territorio del Conurbano como un recorte válido para el estudio de las dinámicas económicas y sociales del sector de la economía popular.

Un aspecto clave para el abordaje esta economía desde las estrategias que la constituyen es redimensionar el papel de la división sexual del trabajo. Dicha división, supone la segregación de las mujeres a las tareas domésticas y de cuidado, una menor tasa de actividad laboral, ${ }^{12}$ la distribución jerarquizada en las ramas de actividad, en los procesos de organización del trabajo, salariales, en puestos y calificaciones (Ginés, 2009). La forma que adopta tal división sexual es dinámica e histórica, sin embargo, sigue perpetuando la subordinación de las mujeres a la opresión patriarcal y la explotación capitalista bajo nuevas modalidades.

\section{Resultados de investigación}

En la primera etapa de investigación, me orienté al estudio de las condiciones de trabajo de las mujeres de los barrios San Ignacio y La Morita del Partido de Esteban Echeverría, ubicados en el segundo 
cordón del Conurbano bonaerense. Si bien mi interés estaba centrado en las trabajadoras, consideré pertinente analizar los distintos indicadores laborales (estabilidad, calificación, formalidad, tipo de ocupación, categoría laboral) observando los resultados a partir de la variable género, incluyendo a los varones en las mediciones. ¿qué características tienen las trabajadoras de los barrios estudiados?, ¿qué factores inciden en los modos y condiciones en que se insertan?, ¿Qué diferencias/similitudes existen entre los trabajadores y las trabajadoras en relación con esas condiciones de inserción?, fueron algunos de los interrogantes que dieron paso a la elaboración esta primera etapa de mi proyecto.

Para la realización de este estudio, utilicé los resultados de un censo implementado en San Ignacio y La Morita durante mayo de $2016 .{ }^{13}$ Se relevaron de forma efectiva 130 viviendas, 133 hogares y 516 personas. ${ }^{14}$ De dicha base de datos, seleccioné a varones y mujeres mayores de 14 años que conformaron una nueva base de 186 casos totales entre ocupados/as y desocupados/as pertenecientes a la Población Económicamente Activa (PEA) de los barrios seleccionados. Los datos relevados arrojaron una importante presencia de trabajadores/ as informales, con empleos precarios e inestables ${ }^{15}$ y bajo nivel educativo. Asimismo, un rasgo importante de esta población es el peso de las políticas sociales como fuente de ingreso, demostrando la articulación de estrategias y recursos para el sostenimiento de las economías de los hogares. Esto se demuestra con mayor evidencia en el caso de las trabajadoras y en los hogares cuya jefatura es de mujeres.

La PEA ${ }^{16}$ de ambos barrios registra un 95\% de ocupación, existiendo un bajo porcentaje de trabajadores y trabajadoras sin empleo. Este dato da cuenta también de la proliferación de estrategias laborales que se dan en los habitantes de estos barrios para garantizar un ingreso básico para su subsistencia. En el Gráfico 1 se puede observar su composición según género, allí encontramos que el 65,6\% son varones y el 34,4\% son mujeres. Esta diferencia notable en la participación es significativa, superando incluso los datos que se observan en la PEA del Conurbano bonaerense: 70,5\% y 48,3\% respectivamente registrados en el mismo periodo por la Encuesta Permanente de Hogares. ${ }^{17}$

\section{GRÁFICO 1}

Población económicamente activa de San Ignacio-La Morita según género

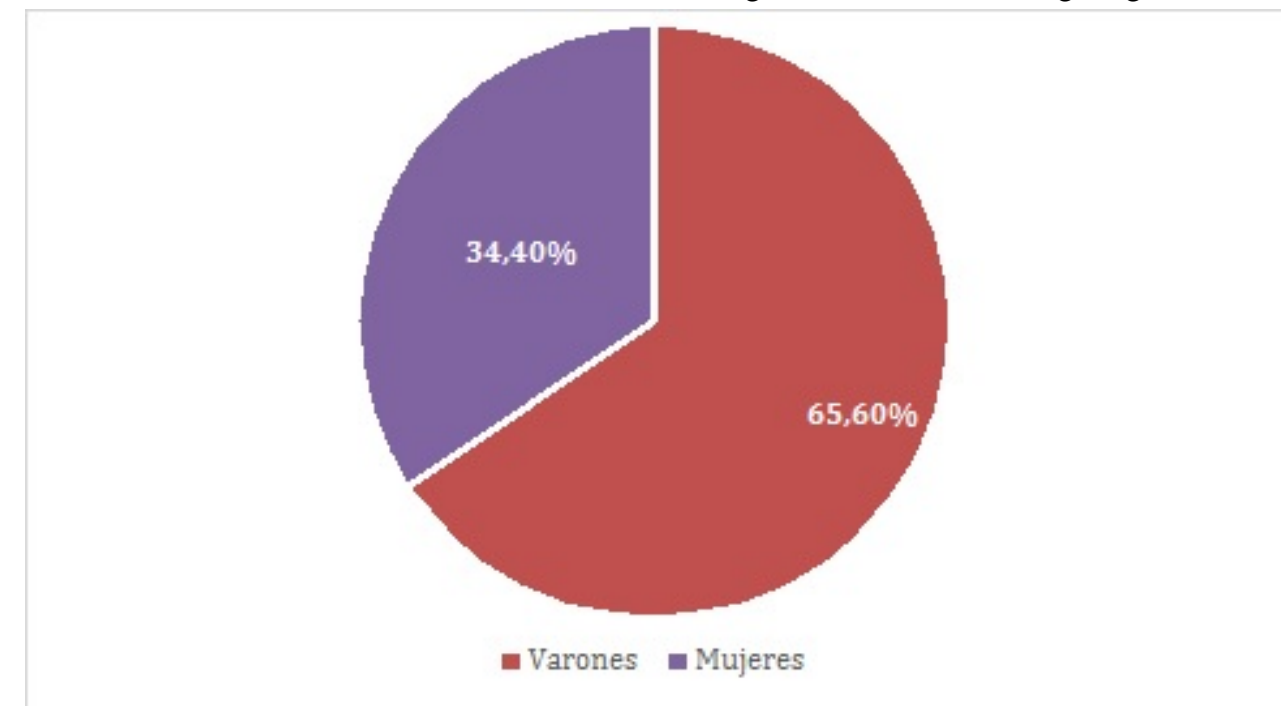

Fuente: Elaboración propia con base en relevamiento PEC-UNDAV, mayo 2016.

Es posible arriesgar dos hipótesis respecto al resultado de este primer cuadro. La primera es que la conjunción de las demandas domésticas, la posición subordinada de las mujeres en la división sexual del trabajo y las representaciones construidas en torno a su papel en la vida doméstica condicionan su incorporación al ámbito laboral remunerado. La segunda es que las modalidades precarias e inestables de trabajo que implican jornadas extenuantes para garantizar un ingreso básico para los hogares también 
operan como un factor de "desaliento" y obligan a las mujeres a recurrir a otras estrategias posibles para la supervivencia. A esto, debemos sumar la cantidad de horas invertidas y el costo en el traslado hacia los lugares de trabajo de las mujeres de San Ignacio y La Morita. Esta combinatoria evidencia la dependencia e interrelación de las trayectorias laborales al ciclo vital personal y familiar de las trabajadoras, operando esta dimensión de manera diferencial en el caso de los varones que guardan mayor independencia en la relación entre inserción laboral y las obligaciones domésticas y de cuidado.

El tipo de ocupación que se registra en los casos relevados muestra claramente el peso de la división sexual del trabajo remunerado en la imbricación de las estrategias de reproducción vinculadas al mundo laboral. Si observamos la Tabla 1 encontramos dos ocupaciones que aparecen como principales canales de absorción de la fuerza de trabajo feminizada en los barrios en estudio: el empleo doméstico remunerado y actividades laborales vinculadas al recupero y reciclado de residuos, metales, plásticos, etc., mientras que en tercer lugar se registran ocupaciones en comercio y venta. ${ }^{18}$

TABLA 1

Ocupación de las mujeres en barrio San Ignacio

\begin{tabular}{|l|l|l|}
\hline Ocupación & Casos & Porcentaje \\
\hline Personal doméstico & 22 & 34,9 \\
\hline Reciclado (residuos, metales, plásticos) chatarrera/o & 8 & 12,7 \\
\hline Acompañantes y ayudante de cámara & 5 & 7,9 \\
\hline Vendedoras de tiendas y almacenes & 5 & 7,9 \\
\hline Limpiadores/as de oficinas, hoteles y otros establecimientos & 4 & 6,3 \\
\hline Telefonistas & 3 & 4,8 \\
\hline Cocineros/as & 3 & 4,8 \\
\hline Vendedores/as de quioscos y puestos de mercado & 3 & 4,8 \\
\hline Vendedores/as a domicilio y por teléfono & 3 & 4,8 \\
\hline Camareros/as taberneros/as & 1 & 1,6 \\
\hline $\begin{array}{l}\text { Peluqueros/as, especialistas en tratamiento de belleza } \\
\text { afines }\end{array}$ & 1 & 1,6 \\
\hline Policías & 1 & 1,6 \\
\hline Promotores/as de venta & 1 & 1,6 \\
\hline Vendedores/as ambulantes de productos comestibles & 1 & 1,6 \\
\hline Embaladores/as manuales y otros peones de la indurera & 1,6 \\
\hline Total & 1 & 1,6 \\
\hline
\end{tabular}

Fuente: Elaboración propia en base a relevamiento PEC-UNDAV, mayo 2016. 
En el Gráfico 2 los resultados señalan que solo el 36,3\% de las trabajadoras posee algún tipo de calificación, ${ }^{19}$ mientras que el $61,9 \%$ no poseen ninguna. En el caso de los varones se registra una proporción contraria: el $61 \%$ de los trabajadores tiene calificación frente al 39\% que no posee. Como se puede observar, es notable la diferenciación según el género en este aspecto. Lo cierto es que a través de las distintas entrevistas realizadas a las trabajadoras acerca de sus trayectorias laborales se evidenciaron los distintos obstáculos institucionales y del orden familiar que obstaculizaron sus posibilidades de formación y/o acceso a oficios por fuera de las ofertas tradicionales (costura, limpieza, cuidado). Sumado a esto, su inserción mayoritaria en actividades vinculadas al trabajo doméstico supone la puesta en práctica de saberes "innatos" de las mujeres que no requerirían mayores calificaciones que las adquiridas a lo largo de su crianza. Las propias taxonomías con las que se miden estas ocupaciones incurren en señalar que se trata de empleos que no requieren mayor tecnificación ni "capacidades de juicio".

Las clasificaciones que se utilizan habitualmente en el mundo laboral están atravesadas fuertemente por la construcción desigual de los atributos y de una valoración diferencial de las capacidades de varones y mujeres que se luego se refleja en el funcionamiento del mercado de trabajo, sus mecanismos de acceso y en la legislación e instituciones laborales.

GRÁFICO 2

Mujeres y varones de la PEA según calificación en porcentajes

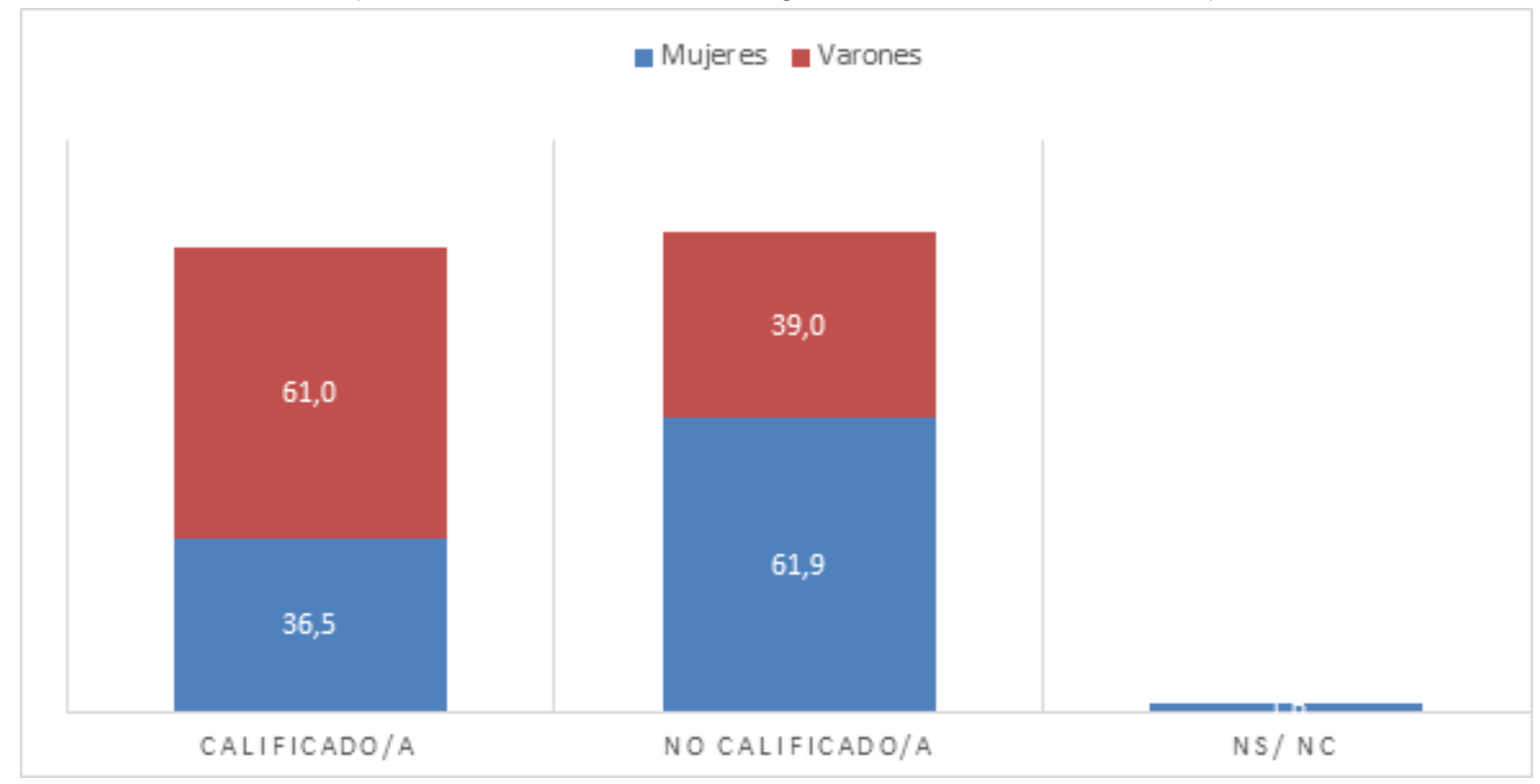

Fuente: Elaboración propia en base a relevamiento PEC-UNDAV, mayo 2016

Otro indicador relevante que nos permite caracterizar las condiciones laborales de las mujeres del barrio San Ignacio y La Morita tiene que ver con la estabilidad laboral. En el Gráfico 3 podemos observar que el $60,3 \%$ de las mujeres tiene trabajos transitorios, changas o por tarea frente al 34,9\% que lo hace de manera estable o fija. En el caso de los varones quienes tienen empleos considerados inestables representan el 56,1\% y aquellos que se ocupan de manera estable el 43,9\%. Como podemos observar la inestabilidad es un rasgo transversal a los trabajadores y trabajadoras pero que, sin embargo, se manifiesta en mayor medida en el caso de las mujeres. 


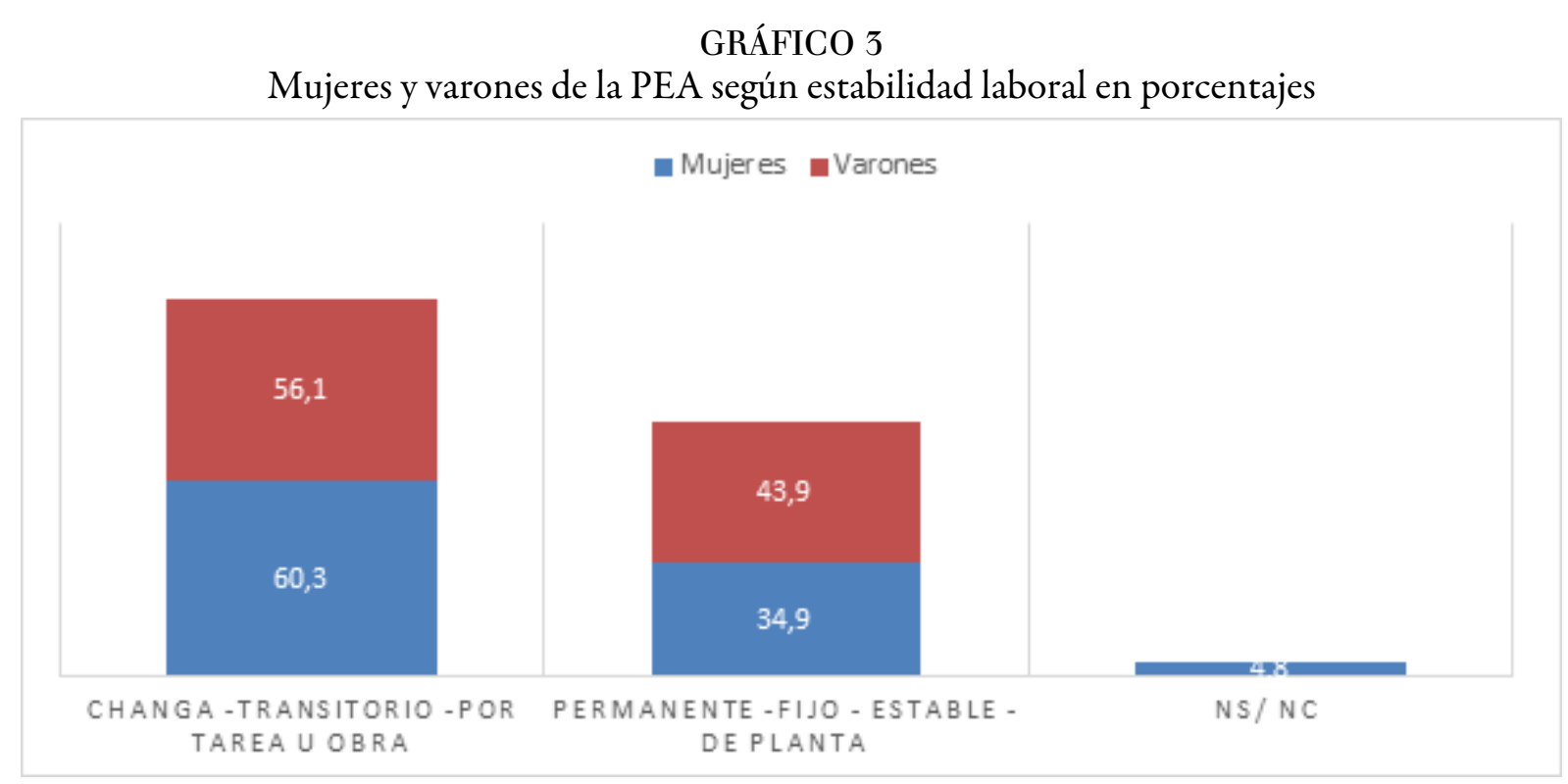

Fuente: Elaboración propia en base a relevamiento PEC-UNDAV, mayo 2016.

La informalidad ${ }^{20}$ aparece como un rasgo predominante (aunque no excluyente) de la economía popular y de las condiciones de inserción de sus trabajadores/as. En relación con este indicador las mujeres ocupadas de San Ignacio y La Morita registran un 78,7\%, que en el caso de los varones alcanza el 75,9\%. Estos elevados porcentajes evidencian una importante proporción de la fuerza de trabajo totalmente desprovista de protecciones sociales (ausencia de aportes jubilatorios, cobertura social, licencias, seguro frente a los riesgos del trabajo, entre otros derechos básicos). Si bien los hogares con jefatura femenina registrados son considerablemente menores en la mayoría de los casos, aquellos que están sostenidos por mujeres que tienen trabajos no registrados. Las implicancias de esta condición para estos hogares se demuestra en las dificultades cotidianas para el acceso a los recursos necesarios, protecciones en salud, licencias y aportes jubilatorios. En el Gráfico 4 se pueden observar las proporciones:

GRÁFICO 4

Mujeres y varones de la PEA según formalidad/informalidad

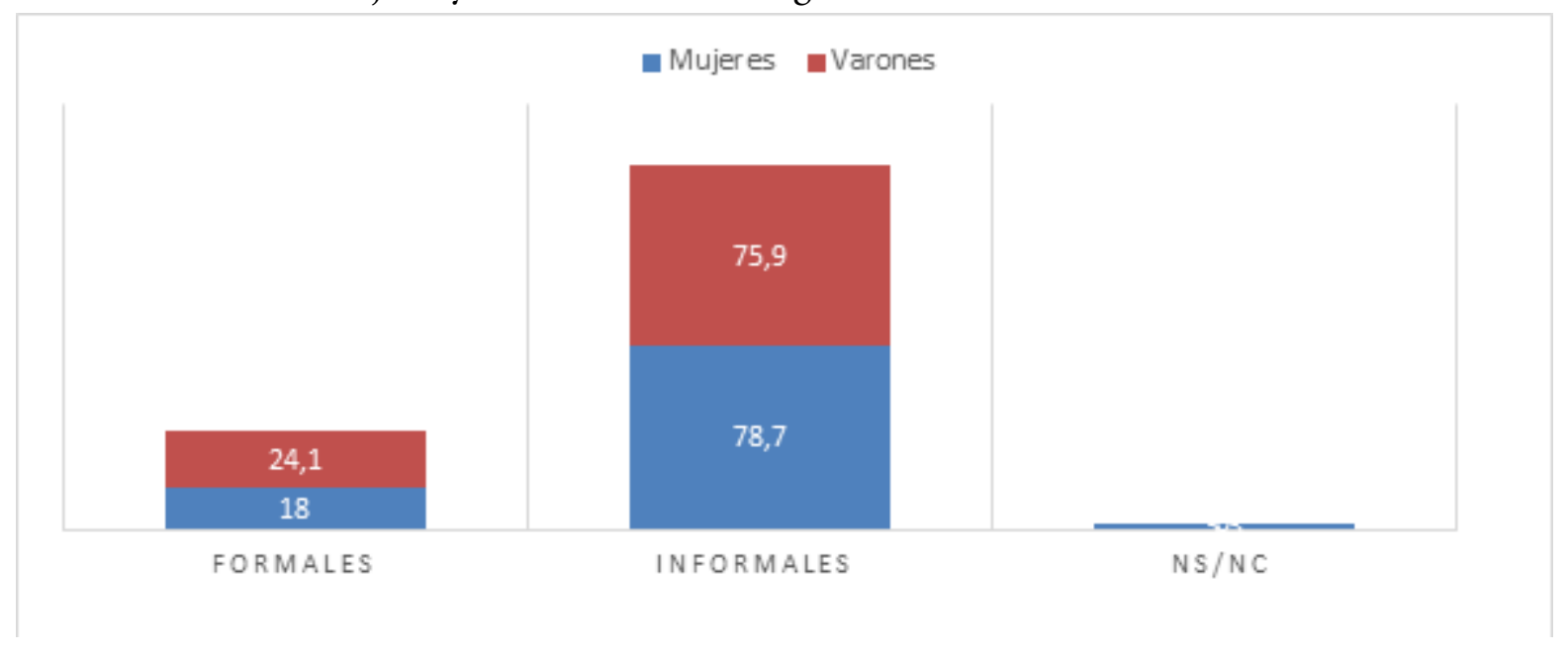

Fuente: Elaboración propia en base a relevamiento PEC-UNDAV, mayo 2016.

En relación con la categoría laboral, los datos registrados permiten observar cómo mujeres y varones mantienen proporciones similares respecto al trabajo en relación de dependencia y por cuenta propia: cerca 
del $57 \%$ trabaja en relación de dependencia, mientras que el $41 \%$ lo hace por cuenta propia. El trabajo por cuenta propia puede ser visto como una chance de autogeneración de empleo e ingresos que no siempre va acompañada de una decisión autónoma de las personas. Esta modalidad por lo general conlleva a asumir los costos de la precariedad e informalidad que ofrecen las actividades más recurrentes en la economía popular (reciclado, venta ambulante, pequeños talleres de reparación, servicios técnicos). Para los varones esta modalidad aparece relacionada con la imposibilidad de insertarse de manera estable en el mercado, mientras que en el caso de las mujeres según sus relatos en las entrevistas se vincula a la necesidad de encontrar alternativas laborales que sean compatibles las demandas domésticas y de cuidado en materia de horario y "flexibilidad". Las oportunidades de trabajo en relación de dependencia resultan muy restringidas para aquellas mujeres que no cuentan con apoyo ni instituciones de cuidado infantil. Sin embargo, la falta de protecciones sociales que conllevan las actividades laborales por cuenta propia, si bien proporcionan un ingreso, recrudece notablemente las condiciones de vida de los hogares cuyas trabajadoras se encuentran en esta situación.

En cuanto a las políticas sociales y su presencia en la PEA, el Gráfico 5, muestra una importante incidencia en las estrategias de obtención de ingresos en el caso de las mujeres $(27,0 \%)$ y su menor proporción entre los varones (5,7\%). Los programas, particularmente aquellos que otorgan transferencias monetarias, se constituyen como un elemento de peso en las economías domésticas y resultan imprescindibles para complementar los recursos. Los datos registrados guardan estrecha relación con una creciente tendencia a la feminización de la política social. Al mismo tiempo este fenómeno da cuenta del perfil de las intervenciones del Estado en tanto las condicionalidades exigidas por los programas, siempre en primer término a las mujeres a través de los controles de asistencia escolar y de salud de los/as hijos/as a cargo, reafirman estereotipos basados en atributos naturalizados en los cuerpos feminizados como los únicos capaces de atender correctamente las demandas domésticas y de cuidado. ${ }^{21}$

\section{GRÁFICO 5}

Mujeres de la PEA según percepción de planes sociales

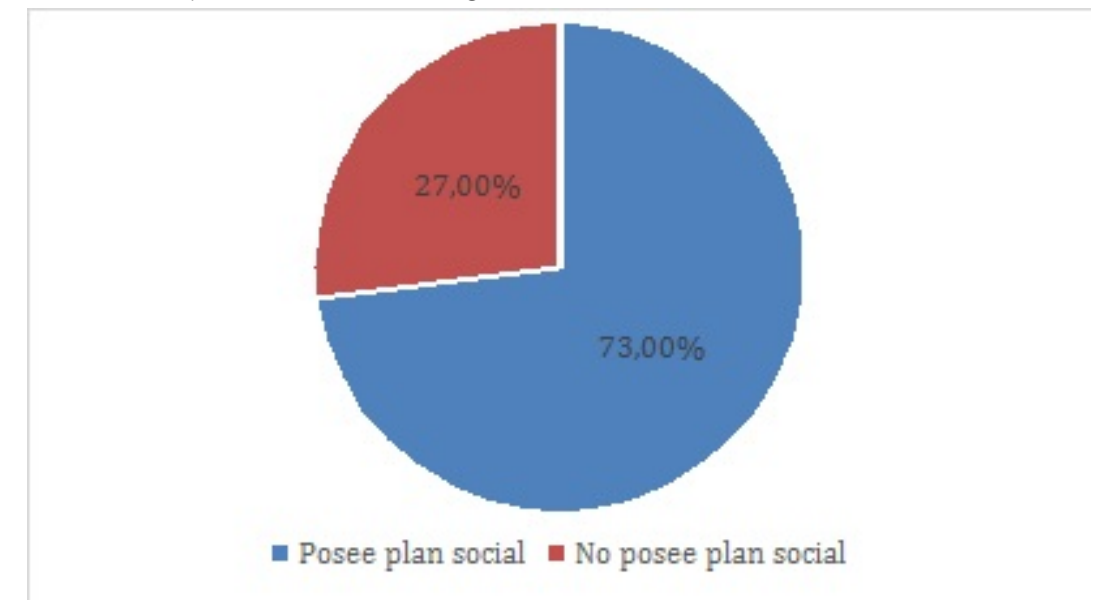

Fuente: Elaboración propia en base a relevamiento PEC-UNDAV, mayo 2016

Si se analizan los hogares en función de las jefaturas de varones y mujeres se encontró que el 53,9\% de las trabajadoras son jefas de hogar, mientras que en el caso de los varones este porcentaje asciende al 80,4\%. Los datos analizados muestran que, si bien en los núcleos familiares comandados por mujeres tienen como fuente principal de ingresos la laboral alcanzando un 48,5\%, en segundo lugar, encontramos nuevamente una importante presencia de las políticas sociales que llegan a representar el 33,3\%. En cuanto a los hogares con varones jefes el $80,4 \%$ de los ingresos proviene del trabajo y en segundo lugar de las políticas sociales, pero ya desciende considerablemente esta proporción a un $12,4 \%$. Dentro del grupo de mujeres que reciben 
algún tipo de asistencia o programa social, el 36,4\% percibe la Asignación Universal por Hijo (AUH) y el 16,7\% el programa Tarjeta Más Vida para la compra de alimentos. Las políticas que requieren algún tipo de contraprestación laboral se concentran en el Programa Argentina trabaja a través de las cooperativas de trabajo. Sin embargo, el porcentaje de participación y de presencia de esta modalidad es considerablemente bajo en los barrios estudiados.

\section{GRÁFICO 6}

Jefatura por género según principal fuente de ingresos

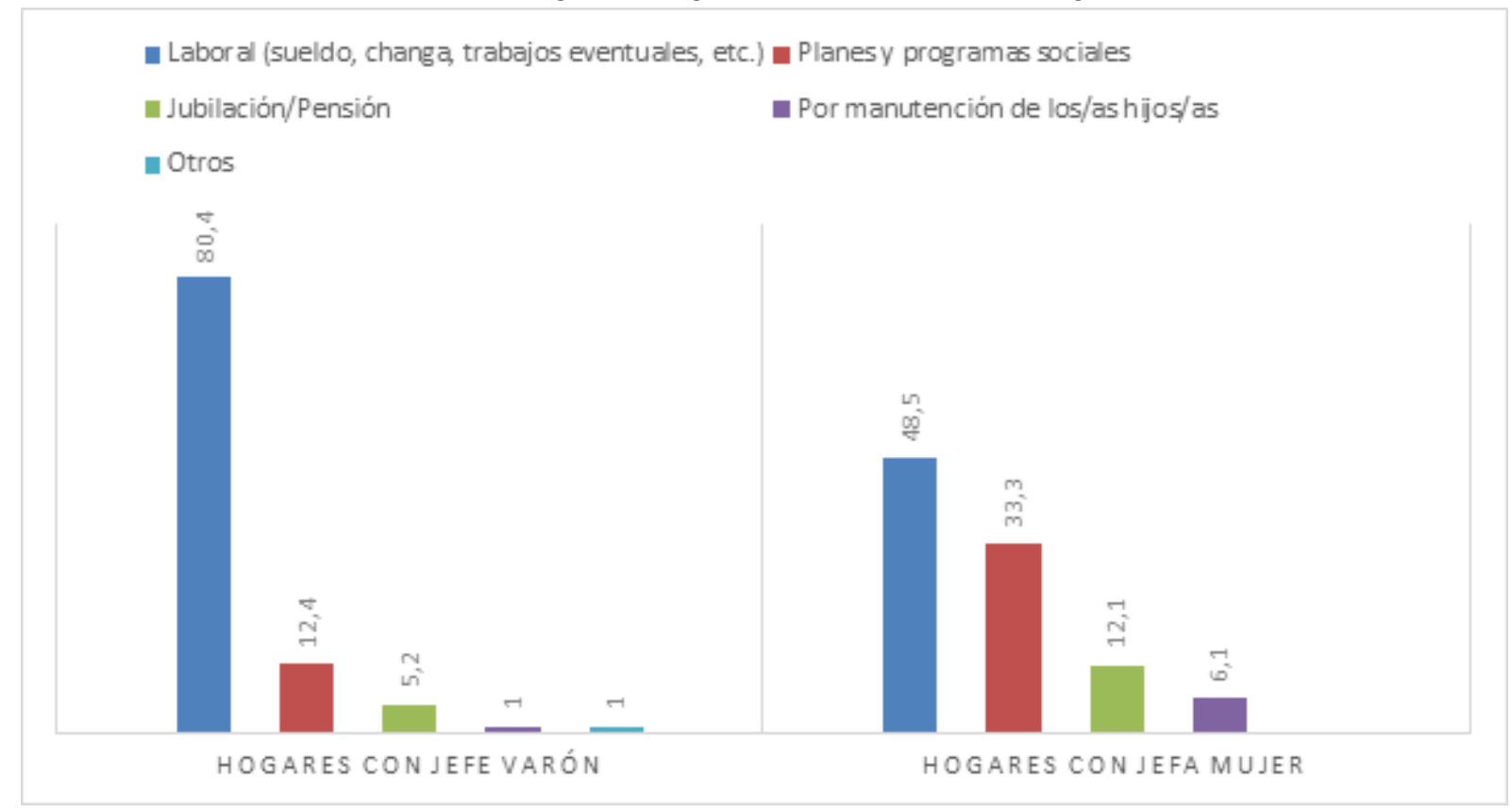

Fuente: elaboración propia en base a relevamiento PEC-UNDAV, mayo 2016

Otro dato significativo tiene que ver con el lugar donde las mujeres y los varones de los barrios en estudio realizan su trabajo. Una proporción importante lo hace en la Ciudad de Buenos Aires (20,6\% de las mujeres y en el caso de los varones solo el 10,0\%) y dentro del propio Municipio de Esteban Echeverría. Las distancias locales respecto a la ciudad capital implican tiempos y costos de traslados que, sumado a las responsabilidades domésticas cotidianas, resultan una presión sobre los tiempos y en la capacidad económica de las trabajadoras de solventar esos gastos de transporte frente a los bajos ingresos que perciben.

También es importante la proporción de mujeres que realizan su trabajo dentro del hogar alcanzando un $12,7 \%$ mientras que los varones solo representan el 3,3\%. Esto podría suponer la posibilidad de compatibilizar el trabajo remunerado que realizan las mujeres para la obtención de ingresos con las responsabilidades domésticas y de cuidado. Sin embargo, la simultaneidad de tareas productivas y reproductivas que realizan las mujeres diariamente en sus hogares es señalado en las entrevistas como uno de los mayores factores de agotamiento físico y mental que padecen.

Una característica de la población de ambos barrios es la presencia mayoritaria de personas jóvenes y niños/as. Si bien estadísticamente la participación de las mujeres es baja y el total de casos no es de un impacto significativo, analizar los datos de este grupo de trabajadoras resultó teóricamente relevante debido a que posibilitó una mirada sobre las reconfiguraciones del trabajo y de la clase trabajadora, ponderando las implicancias de la dimensión de género en estas transformaciones. Observar en particular las trayectorias de las mujeres de San Ignacio y La Morita permite, asimismo, situar los indicadores en estudio en el entramado territorial de los barrios populares del Conurbano. Este "situar" es comprender al territorio como un espacio de relaciones sociales con características específicas que configuran una parte importante de las condiciones en que se despliegan las estrategias cotidianas para la reproducción de la vida. 
Por último, en las entrevistas en profundidad realizadas a las trabajadoras de los barrios en estudio se evidencia el peso de las redes territoriales de intercambio y ayuda. El concepto de redes se torna central para designar a las distintas articulaciones que se despliegan entre vecinos/as, organizaciones, trabajadores/as y hogares para diversos fines y que guardan estrecha relación con la reproducción ampliada de la vida. Estas redes permiten la obtención de recursos, intercambios, reposicionamiento en los vínculos de poder territorial, entre otras dimensiones. No designan de por si relaciones simétricas u horizontales y pueden ser prolongadas o coyunturales y son mayoritariamente integradas y articuladas por las mujeres. El peso del territorio en la conformación de los circuitos donde se tejen redes entre vecinos es fundamental para el acceso de los hogares a las oportunidades laborales, políticas y programas sociales que contemplan también la incorporación a cooperativas o participación en trabajos comunitarios. ${ }^{22}$

\section{TraYeCtorias EN TENSIÓN: TRABAJO REMUNERADO Y HOGAR}

En las distintas entrevistas realizadas pude registrar las permanentes tensiones y sentimientos de frustración que expresaban las mujeres frente a las múltiples exigencias domésticas y las demandas de cuidado hacia los miembros del hogar. La maternidad aparece en los relatos como un aspecto definitorio en los recorridos laborales, que obliga a las mujeres a abandonar empleos o bien a insertarse en ocupaciones de poca carga horaria, bajas remuneraciones y sumamente precarias como consecuencia de la falta de infraestructura pública de cuidado para los niños y las niñas que residen en La Morita y San Ignacio. ${ }^{23}$ Este mismo fenómeno puede observarse en relación con las trayectorias educativas inconclusas. Sin embargo, la incorporación al mundo del trabajo, a pesar de las intermitencias, ocurre a corta edad a causa de la necesidad de aportar ingresos a la economía familiar.

Asimismo, en las diferentes entrevistas realizadas se evidencia la persistencia de "arreglos conyugales" que responden a estructuras familiares sostenidas bajo el modelo de varón proveedor. Cuando se disuelven los vínculos matrimoniales son las mujeres quienes afrontan junto a sus hijos las mayores dificultades económicas. La constitución de parejas y las rupturas conyugales también aparecen como un factor con fuerte incidencia en la participación de las trabajadoras en la actividad económica. Sin embargo, sin reconocimiento social ni familiar, son finalmente las mujeres quienes ofician de "doble proveedoras" en la medida en que, además de garantizar una parte fundamental de los ingresos de estos hogares, también posibilitan el bienestar de sus familias con el trabajo de cuidados y domésticos que realizan.

El análisis de las entrevistas también arrojó datos significativos sobre las condiciones en que las mujeres despliegan el trabajo doméstico cotidiano, incluyendo aquellas tareas de cuidados de niños, niñas y personas adultas dependientes de mayor demanda (ancianos y/o personas con dificultades severas de salud). La autopercepción y adjudicación de las tareas que corresponden a las funciones que competen a la "ama de casa" están presentes en los relatos de las mujeres. La propia atribución de responsabilidades da cuenta de una división sexual del trabajo que opera permanentemente en la distribución de los cuerpos y moldea subjetividades. El trabajo doméstico en los hogares en estudio requiere del despliegue de un conjunto más amplio de acciones y actividades que excede las tradicionalmente estipuladas (aseo, alimentación, cuidado, entre las más típicas). En complemento con otras estrategias permite el sostenimiento de las condiciones de vida del conjunto del hogar y de los entramados territoriales que en la economía popular caracterizan su dinámica de las estrategias de reproducción.

En contextos de ajuste estructural el trabajo no remunerado de las mujeres se posiciona como recurso esencial para garantizar la satisfacción de necesidades básicas y reemplazar, frente a la falta de dinero y protecciones sociales y de aquello que podía adquirirse a través del mercado o el Estado. En consecuencia, el trabajo en el hogar se extiende en el tiempo, se intensifica en su aspecto manual debido a la falta de acceso a las tecnologías domésticas (se lava en baldes grandes de pintura por falta de lavarropas, se cocinar con leña por 
carencia de gas o recursos para obtener garrafas, entre los ejemplos más comunes, se "peregrina” en búsqueda de bienes a bajo o sin costo, o bien para la obtención de ayudas o redes de apoyo).

Una parte importante de las mujeres que residen en San Ignacio y La Morita venden su fuerza de trabajo en otros hogares asistiendo en la vida doméstica a otras que bajo mejores condiciones logran tercerizar los requerimientos del hogar y el cuidado de sus miembros. Los relatos de las entrevistadas dan cuenta de largas jornadas de trabajo doméstico dentro y fuera, sin descansos y que las mantiene en un alto nivel de exigencia física y emocional, principalmente por el acuciante contexto económico y de recursos en que deben resolver las demandas del hogar.

El voluminoso trabajo no remunerado que realizan las mujeres de los sectores populares se sostiene sobre el reforzamiento de la división sexual del trabajo. Los límites de las viviendas en los barrios populares no son necesariamente fronteras reales del "mundo doméstico privado", en tanto otro rasgo particular es la articulación en red que despliegan las mujeres para resolver la cotidianeidad dentro del territorio donde residen. Dichas redes posibilitan vínculos vecinales y entre hogares para la reproducción cotidiana, la obtención de recursos comunes, la atención y cuidado de niños, entre otras prácticas comunes que hacen "correr" los límites entre lo público y privado.

Sobre las mujeres recaen responsabilidades y múltiples intervenciones -que incluyen dispositivos de control y disciplinamiento- como producto de la combinación y los mecanismos de reproducción capitalista y patriarcal que ordenan cuerpos y regulan las relaciones sociales, culturales, políticas y económicas en nuestra sociedad actual.

\section{A MODO DE CONCLUSIÓN}

A lo largo de este artículo, se buscó dar cuenta un proceso creciente en la dinámica social argentina. Dicho proceso posiciona a la economía popular como la expresión de un sector de la población que intenta resolver su reproducción cotidiana articulando estrategias posibles en un contexto de precariedad e informalidad preocupante. Estas experiencias evidencian también la importancia que cobra el trabajo de las mujeres, remunerado y no remunerado, en las estrategias de reproducción de las clases populares que son el motor de esta economía. En tal sentido, las reflexiones y el análisis aquí planteados puede servir para pensar plantea algunos desafíos para las economías populares y su inserción territorial, y la capacidad de sus agentes y organizaciones de jugar en el escenario político y disputar sentidos, políticas y reivindicaciones.

En los datos aquí presentados, se pudieron observar algunas de las características y condiciones de inserción de las trabajadoras de los barrios en estudio: la articulación de la política social con el trabajo remunerado, una importante presencia de informalidad en las distintas modalidades de inserción. Asimismo, dificultades en el acceso a la educación y a la calificación laboral debido a las carencias y vulnerabilidades económicas a las que están expuestas desde temprana edad, así como también por el importante peso demandas domésticas y la persistencia de estereotipos de género que reducen las alternativas para las trabajadoras.

También, se han evidenciado las dificultades que tienen las trabajadoras a lo largo de sus trayectorias para la continuidad de su formación educativa y en materia de calificación laboral. Dos factores se interrelacionan en esta dimensión: las condiciones de vulnerabilidad socioeconómica que padecen sus hogares de origen, así como también el importante peso demandas domésticas y de cuidado sumado a la reproducción y persistencia de estereotipos de género a las que son expuestas desde temprana edad.

El ajuste se evidencia en los hogares de los sectores populares redoblando el trabajo de las mujeres. La incorporación al mundo del trabajo es a través de ocupaciones que proporcionan bajos ingresos y mayoritariamente inestables. El cuidado y el trabajo doméstico siguen perpetuándose como una tarea exclusiva de las mujeres que tiene un importante papel en la satisfacción de múltiples necesidades y demandas en los hogares. Sostienen la autoconstrucción y mantenimiento de las viviendas, la provisión de servicios, las redes que permiten obtener recursos, entre otras necesidades. A través de las tareas no reconocidas como 
trabajo y sin remuneración recaen sobre estos cuerpos no solo las responsabilidades del sostenimiento de los hogares, sino también las múltiples intervenciones y dispositivos de control y disciplinamiento como parte del andamiaje y entrecruzamiento de los mecanismos de reproducción capitalista y patriarcal de nuestra sociedad en su más cruda expresión.

Asimismo, los resultados motivan algunas reflexiones en torno a los modos que adquieren las intervenciones estatales en este sector, el diseño de las políticas sociales, su capacidad de condensar matrices paternalistas y sus posibilidades de ruptura. En este sentido, es necesario replantear la orientación y los objetivos que se plantean desde la política pública en relación con la articulación de propuestas que permitan "equilibrar" la lucha contra las desigualdades económicas de la construcción de mejores condiciones para lograr erradicar la desigualdad de género. El desafío que nos queda por delante, principalmente al campo de la investigación social, es la construcción de herramientas teorías y metodológicas que permitan un abordaje integral de los vínculos entre producción y reproducción.

Por último, señalé con insistencia a lo largo de este artículo que en la matriz de la economía popular se pone de manifiesto la centralidad de las mujeres en el engranaje de su funcionamiento. Esto es porque el trabajo de las mujeres, en su acepción más amplia, permite abaratar los costos que conlleva la reproducción de la fuerza de trabajo, pero, además, a través de la precarización de sus condiciones laborales garantiza nuevas modalidades de extracción de ganancias para el capital, aun en los márgenes de la economía informal. La imbricación entre el sistema capitalista y patriarcal como una poderosa maquinaria que opera sobre los cuerpos feminizados de las clases populares implica deterioro de sus condiciones de vida y de los hogares y territorios donde intentan desplegar estrategias posibles para la reproducción cotidiana.

El estudio de las dinámicas de las economías y de los trabajadores y las trabajadoras de los sectores populares requiere integrar campos disciplinarios que permitan complejizar la mirada sobre la desigualdad. Sin embargo, más allá de las caracterizaciones, las tensiones en torno a las formas de conceptualizar estas realidades, importa, sobre todo, conocer sus estrategias, sus voces y resistencias que son tejidas cotidianamente desde los territorios para pensar posibles horizontes para la transformación de las condiciones que generan desigualdad y violencia.

\section{REFERENCIAS Bibliográficas}

Beccaria, L. y Maurizio, R. (2004). Inestabilidad laboral en el Gran Buenos Aires. El Trimestre Económico vol. LXXI (3) $283,535-573$

Bourdieu, P. (2000). Espacio Social y Poder Simbólico. Cosas dichas (pp.127-142). Barcelona: Gedisa

Bourdieu, P. (2011). Las estrategias de reproducción social. Buenos Aires: Siglo Veintiuno Editores.

Cabrera, C. y Vio, M. (2014). Cuaderno de Bitácora. Los hilos de la economía popular en la posconvertibilidad. En Cabrera, C. y Vio, M (Coord.). La trama social de la economía popular (pp. 27-42). Buenos Aires: Espacio Editorial.

Carrasco, C. (2006). La paradoja del cuidado: Necesario pero invisible. Revista de economía crítica, 5, 39-64. Recuperado de: http://revistaeconomiacritica.org/sites/default/files/revistas/n5/2_paradoja_del_cuidado.pdf

Coraggio, J. (1998). Economia urbana: la perspectiva popular. Quito: Abyayala, Instituto Latinoamericano de Investigaciones Sociales-FLACSO.

D'Angelo, A. y Martinelli, V. (2015). ¿De qué hablamos cuando hablamos de territorio?: una indagación teóricopráctica”. Ponencia presentada XI Jornadas de Investigación y XI Encuentro Regional SI+TER. Ciudad Autónoma de Buenos Aires. Recuperado de: http://rdd.undav.edu.ar/pdfs/ev6/ev6.pdf

Escobar de Pabón, S. y Guaygua, G. (2008). Estrategias familiares de trabajo y reducción de la pobreza en Bolivia. Buenos Aires: Consejo Latinoamericano de Ciencias Sociales (CLACSO-CROP).

Gago, V. (2014). La razón neoliberal: economias barrocas y pragmática popular. Buenos Aires: Tinta Limón. 
Ginés, M. E. (2009). División sexual del trabajo. En Gamba, S. (Coord.). Diccionario de estudios de género y feminismos (pp. 101-104). 2a ed. Buenos Aires: Editorial Biblos

Gorbán, D. (2014). Las tramas del cartón. Trabajo y familia en los sectores populares del Gran Buenos Aires. Buenos Aires: Editorial Gorla.

Goren, N. (2013). Inequidades Laborales, las brechas de género en el trabajo y en los salarios. Buenos Aires: Centro de Estudios Mujer y Trabajo.

Groisman, E. (2016). Estructura social e informalidad laboral en Argentina. Buenos Aires: EUDEBA.

Gutierrez, A. (2003). La construcción social de la pobreza. Un análisis desde las categorías de Pierre Bourdieu. Revista Andaluza de Ciencias Sociales, 2, 29-44). Recuperado de: https://revistascientificas.us.es/index.php/anduli/art icle/view/3747/3275

Gutiérrez, A. (2015). Pobre... como siempre. Estrategias de reproducción social en la pobreza. Córdoba: Eduvim.

Hintze S. (1987). Crisis y supervivencia: estrategias de reproducción. Revista La Ciudad Futura, 8/9, s/p.

Jelin, E. (2010). Pan y afectos. La transformación de las familias. Buenos Aires: Fondo de Cultura Económica.

Kandel, E. (2006). División sexual del trabajo ayer y hoy: una aproximación al tema. Buenos Aires: Dunken.

Kessler, G., Svampa, M., \& González Bombal, I. (2010). Reconfiguraciones del mundopopular. El Conurbano Bonaerense en la postconvertibilidad. Buenos Aires: Prometeo.

Lepore, S., y Salvia, A. (2002). Segmentación socio-ocupacional y precariedad del bienestar en los hogares. Buenos Aires: Instituto para la Integración del Saber/ Departamento de Investigación Institucional - UCA.

Massa, L. (2010). Estrategias de reproducción social y satisfacción de necesidades. Parte I: Controversias conceptuales, polémicas prácticas. Revista Perspectivas Sociales Primavera, 12(1), 103-140. Recuperado de: http://eprints.uan l.mx/8711/1/art4\%20\%282\%29.pdf

Muñiz Terra, L., Roberti, L., Deleo, C. y Hasicic, C. (2013). Trayectorias laborales en Argentina: una revisión de estudios cualitativos sobre mujeres y jóvenes. Revista Lavboratorio, 25, 57 - 79. Recuperado de: http://publica ciones.sociales.uba.ar/index.php/lavboratorio/article/view/119/0

Neffa, J. (2008). La informalidad, la precariedad laboral y el empleo no registrado en la provincia de Buenos Aires. Buenos Aires: CEIL-PIETTE/Ministerio de Trabajo de la Provincia de Buenos Aires.

Neffa, J. (2010). El trabajo no registrado como modalidad límite de precariedad. En Busso, M. y Pérez, P. (comp.). La corrosión del trabajo. Estudios sobre informalidad y precariedad laboral. Buenos Aires: Miño y Dávila.

Pérez Orozco, A. (2014). Subversión feminista de la economía. Aportes para un debate sobre el conflicto capital-vida. Madrid: Traficantes de sueños.

Pok, C. (1992). Precariedad laboral: personificaciones sociales en la frontera de la estructura del empleo. Documento de trabajo presentado en el Seminario Interamericano de Medición del Sector Informal. COM/CIE OE/INEI. Recuperado de: http://www.ceil-conicet.gov.ar/?attachment_id=7110

Rodríguez Enríquez, C. (2015). Economía feminista y economía del cuidado. Aportes conceptuales para el estudio de la desigualdad. Revista Nueva Sociedad, 256, 30-44. Recuperado de: https://nuso.org/media/articles/downloa ds/4102_1.pdf

Tizziani, A. (2011). De la movilidad ocupacional a las condiciones de trabajo. Algunas reflexiones en torno a diferentes carreras laborales dentro del servicio doméstico en la Ciudad de Buenos Aires. Revista Trabajo y Sociedad UNSE, $X V(17), 309-328$. Recuperado de: http://www.scielo.org.ar/pdf/tys/n17/n17a19.pdf

Vio, M. (2014). Mundo Desecho. Economía popular y basura en la posconvertibilidad. En C. Cabrera y M. Vio (coord.) La trama social de la economia popular (pp.207-238). Buenos Aires: Espacio Editorial.

Vio, M. (2017). Clases populares, economía popular y Conurbano posconvertibilidad: entre la teoría y la economía popular realmente existente. Ponencia presentada en X Jornadas de Economía Critica. Universidad de General Sarmiento: Los Polvorines. 


\section{Notas}

1 Existe gran cantidad de investigaciones y trabajos en torno a la conceptualización de la precariedad en el campo de estudios local (Neffa, 2010, 2008; Beccaria y Maurizio, 2004, entre otros). Si bien en este artículo por cuestiones de extensión omito los principales debates al respecto, la perspectiva adoptada en este trabajo considera que la precarización reúne un conjunto de dimensiones que se vinculan con aspectos económicos, sociales y jurídicos. La noción de precariedad refiere a las formas que adopta la inserción de los trabajadores y las trabajadoras (con formas de contratación inestable y/o sin acceso a los derechos laborales ligados al registro formal del trabajo).

2 Esta propuesta parte de un proyecto de investigación más amplio que analiza las distintas estrategias de reproducción que despliegan los sectores populares que habitan en el Conurbano bonaerense. Dicho proyecto es parte de las actividades de investigación-transferencia que realiza desde 2011 el Programa de Estudios del Conurbano - CIDIPROCO de la Universidad Nacional de Avellaneda.

3 El Conurbano puede ser observado más que como un recorte geográfico, por su especificidad en términos socioeconómicos, culturales y políticos En dicho conglomerado, que consta de 24 partidos que rodean a la Ciudad de Buenos Aires, se distinguen un primer y un segundo cordón que responden a diferentes procesos de extensión y consolidación del desarrollo urbano metropolitano. En consecuencia, esta diferenciación se expresa en las estructuras sociodemográficas, el perfil productivo, las condiciones urbanas (principalmente en torno a la infraestructura de redes de servicios básicos), y en las características particulares del tejido urbano de cada cordón.

4 El territorio es entendido como un constructo social que expresa el despliegue de relaciones entre los diferentes agentes sociales dispuestos al juego de la construcción de ese espacio geográfico (Tomadoni, 2007: 58). Desde este mismo enfoque puede pensarse al territorio como la imbricación y articulación entre estructura espacial y estructura social. Quienes habitan los territorios los "hacen" y moldean cotidianamente, conformándose en si como una matriz de existencia social y de reproducción, que cristaliza relaciones sociales, experiencias y representaciones ( $D^{\prime}$ Angelo y Martinelli, 2015).

5 Retomo la noción de propiedades de clase de Pierre Bourdieu (2000). El autor define a la clase social como conjunto de condiciones homogéneas de existencia que producen también un sistema de disposiciones, condicionamientos homogéneos y propiedades comunes (p.100). Las características que delimitan una clase social dependen de dos aspectos que la componen: la condición y la posición y que se expresan en dichas propiedades. En clara ruptura con el pensamiento marxista clásico para Bourdieu las propiedades de una clase no pueden definirse únicamente a partir de las relaciones de producción. Si bien una clase posee propiedades vinculadas a sus relaciones objetivas (y objetivadas) con las demás clases referidas a las condiciones materiales de existencia, también posee propiedades ligadas a las relaciones simbólicas que sostienen los sujetos que pertenecen entre si (incorporadas como habitus) y con las demás (Gutiérrez, 2003). La clase se define entonces no por la suma de las propiedades sino por la estructura de relaciones entre ellas y a los efectos de estas sobre la práctica.

6 Si bien es cierto que una de las características más visibles de la economía popular es su vinculación estrecha con el sector informal por parte de la mayoría de los trabajadores y trabajadoras que la componen, esto no significa que esta economía no incluya modalidades de trabajo registrado.

7 El sector de la economía popular al que hago referencia no se focaliza en las experiencias organizadas o colectivos de trabajadores/as, como por ejemplo la Central de Trabajadores de la Economía Popular, ni tampoco es un modo de denominar indistintamente a los emprendimientos de la economía social y solidaria.

8 La referencia clara en este sentido son los movimientos sociales y las expresiones organizadas de los/as trabajadores/as de la economía popular que en los últimos años han tomado mayor visibilidad, como es el caso de la Central de Trabajadores de la Economía Popular (CTEP). Se definen como una organización gremial independiente de los partidos políticos y representativa de los trabajadores en la lucha por el reconocimiento de derechos y mejores condiciones de trabajo para el conjunto heterogéneo de actividades laborales que componen el sector. La CTEP está integrada por distintas organizaciones y núcleos de trabajadores/as.

9 Siguiendo a Bourdieu (2011), el autor plantea que esta noción no alude a una acción racional con cálculos a fines ni tampoco a una práctica completamente irracional. Se trata más bien del producto del sentido práctico, del conocimiento del "juego" y de las condiciones de posibilidad que nos rodean. Esto se traduce en que dados ciertos factores macroeconómicos y sociales que condicionan, por ejemplo, las formas de inserción laboral, las estrategias remiten a un conjunto de prácticas por medio de los cuales los individuos, los grupos o las familias tienen de manera consciente o inconsciente tienden a conservar, aumentar, mantener o mejorar su posición en la estructura de relaciones de clase.

10 En este sentido, Massa señala en relación con las estrategias que "Estas acciones dan cuenta de un entramado social relacional complejo, donde las condiciones sociales enmarcan las posibilidades y consecuencias de las mismas, independientemente de la "conciencia" o "voluntad" de quienes las ejecutan o intentan hacerlo. Opera, en todos sus sentidos, como una mediación entre las elecciones individuales, las singulares y la estructura social. Estas dimensiones, 
que solo son posibles de ser distinguidas en términos analíticos, dado que unas y otras se configuran, condicionan y modifican mutuamente, son una totalidad que constituye el universo de sentidos, las posibilidades de interpretaciónacción del/en el mundo (...). (2010, pp. 16-17)

11 La noción de fondo de reproducción de los hogares remite al concepto "fondo de trabajo" acuñado por Coraggio (1998). El autor define al fondo de trabajo de una unidad doméstica “(...) como el conjunto de capacidades de trabajo que pueden ejercer en condiciones normales los miembros hábiles de la misma, y su realización abarca sucintamente las formas de: trabajo mercantil por cuenta propia (microemprendimientos), trabajo asalariado, trabajo de producción de bienes y servicios para el autoconsumo, así como el trabajo específicamente dedicado a la formación y capacitación” (p.10)

12 Aunque distintos estudios muestran un proceso de largo alcance respecto a la incorporación masiva de las mujeres al mundo del trabajo, los datos empíricos relevados desde 2011 hasta la actualidad en distintos barrios del Conurbano bonaerense sobre la dinámica de la economía popular muestran que las mujeres tienen menor participación en la actividad laboral.

13 El trabajo de campo respondió al desarrollo de mi tesis de Maestría y se realizó en el marco de un relevamiento censal en los barrios señalados como producto de las actividades de investigación-transferencia que realiza el equipo del Programa de Estudios del Conurbano - UNDAV al cual pertenezco. El objetivo de dicho censo era contribuir a generar información precisa de los habitantes y sus condiciones de vida en vistas a un proceso de relocalización de viviendas linderas con un arroyo contaminada que atraviesa ambos barrios.

14 Respecto a este instrumento implicó un diseño probabilístico estratificado en etapas, con selección sistemática en cada estrato. El marco muestral fue construido a partir de la identificación y conteo de viviendas mediante imagen satelital, y su correspondiente restitución en formato dwg y su posterior identificación en el terreno. Se delimitaron estratos definidos territorialmente y en cada estrato se seleccionarán viviendas de forma sistemática in situ, relevándose luego todos los hogares y todos los individuos residentes en cada vivienda seleccionada.

15 Este indicador se construye a partir de considerar la permanencia/estabilidad laboral o e carácter temporario/changa de las ocupaciones de los/as trabajadores/as.

16 La Población Económicamente Activa la integran las personas que tienen una ocupación o que sin tenerla la están buscando activamente (ocupados y desocupados). En la investigación aquí presentada, a diferencia de la medición que realiza INDEC que incorpora la fuerza de trabajo a partir de los 10 años, registramos la PEA en la población a partir de los 14 años.

17 Registrados en el cuarto informe trimestral 2016 de la EPH publicado por el Instituto Nacional de estadísticas y Censos (INDEC).

18 Sobre experiencias de organización y trabajo de recupero de basura se pueden consultar las investigaciones de Gorbán (2014) y Vio (2014). Asimismo, se puede consultar los trabajos de Tizziani (2011) sobre el empleo doméstico remunerado en Argentina. Los trabajos que abordan las brechas ocupacionales y salariales sirven para complementar un diagnóstico de lo que ocurre en materia de empleo si consideramos al género una variable de peso en la persistencia de las desigualdades (Goren, 2013; Kandel, 2006, entre otras).

19 Para determinar la calificación de las ocupaciones se utilizó la clasificación elaborada por la Organización Internacional del Trabajo (OIT) que comprende un código jerárquicamente estructurado dónde se definen los tipos de ocupación. Esta partir de la Clasificación Internacional Uniforme de Ocupaciones (CIUO) que se ordenan en 10 grandes grupos. Todas las ocupaciones que incluyen estos grupos, excepto las que pertenecen a la categoría 9 , son calificadas.

$20 \mathrm{El}$ indicador quedó constituido por dos categorías: presencia (formal) o ausencia (informal) de registración comprobada a través de la existencia (o no) de recibo de sueldo con firma y sello del empleador, descuento por obra social, descuentos por jubilación.

21 Un dato significativo dentro del grupo de mujeres que reciben algún tipo de asistencia o programa social es que el 36,4\% percibe la Asignación Universal por Hijo. Un aspecto novedoso de esta política fue el reconocimiento de la existencia (y persistencia) de un sector de la población bajo condiciones de informalidad laboral y desprovista de acceso a la protección social. En segundo lugar, aparece, con un 16,7\% el programa Tarjeta Más Vida que brinda acceso a alimentos básico

22 También, estas redes son de gran importancia para obtener recursos básicos incluyen el acceso a infraestructura de servicios como luz y agua, mejoramiento de calles que posibiliten el tránsito, entre otras necesidades básicas del hábitat.

23 Durante el recorrido territorial que realicé en San Ignacio y La Morita no se encontraron instituciones educativas en ninguno de los tres niveles ni centros de cuidados de primera infancia (públicos, comunitarios o privados). Los testimonios de los propios vecinos y vecinas dan cuenta de la dificultad de contar con estos recursos, teniendo que inscribir a sus hijos/as en instituciones por fuera del barrio, con el consecuente costo en tiempo y dinero que deben afrontar los hogares. 